\title{
Evaluating the Effect of Tele-nursing on the quality of life of cancer patients admitted to selected hospitals of Tehran University of Medical Sciences in 2014-2015
}

\author{
Research Article
}

\author{
Azin Chakeri $^{1,2^{*}}$, Shiva Salehi ${ }^{3}$, Zahra Ab Gharebagh ${ }^{4}$, Shima Haghani ${ }^{5}$
}

1. MSc in Psychiatric Nursing, Islamic Azad University, Tehran Medical Branch,Tehran, Iran.

2. Faculty Member, Islamic Azad University, Gramsar Branch, Garmsar Iran.

3. Faculty of Nursing Midwifery, Islamic Azad University, Tehran Medical Branch, Tehran, Iran.

4. Faculty of Nursing Montreal University, Montreal, Canada.

5. School of Public Health, Shahrekord University of Medical Science, Shahrekord, Iran.

\begin{abstract}
Introduction: Patients with cancer experience several physical and psychological problems which decrease their quality of life, compared to the lives of other patients, significantly. Tele-nursing follow-up cares are conducted in such a way that trains nurses in order to improve nursing care and achieve increasing welfare for the patients. The main objective of the present study was to determine the impact of continuing nursing consulting through Tele-nursing on the quality of life of cancer patients. Methods: 60 patients who had recently been diagnosed with colorectal cancer and lung cancer that and hospitalized for the first time for treatment were selected through consecutive sampling as the subjects of the present empirical study. Standardized specific questionnaires were used to collect required data and measure the quality of the life of patients with cancer (QLQ-C30) before and after the intervention. The samples were randomly divided into two groups of control and intervention after running the training program and providing informational pamphlets. Subjects in the intervention completed Telenursing counseling questionnaire against after the intervention and results from pre- and post-training were compared in both groups. Results: The results of the present study showed that the quality of life and its aspects of both groups experienced significant change after training program and Tele-nursing $(p<0.001)$; the average quality of life and its aspects increased after educational programs and Tele-nursing $(\mathrm{p}<0.001)$. Conclusion: This study showed that Tele-nursing can be quite effective in improving the quality of life of cancer patients; thus, it seems scientifically justified that this method be implemented to enhance the quality of life of other chronic illnesses, as well.
\end{abstract}

Keywords: Quality of life of cancer patients, Tele-nursing.

\section{Introduction}

Nowadays, the word 'cancer' is being constantly heard from everywhere all around the world and reports about deaths resulting from this disease have become common gossip. Cancer is considered as a major health problem throughout the world and it is the third common cause of death, after cardiovascular disease and natural disasters, in Iran (1). Yearly, approximately 80 thousand new cases of cancer are reported in Iran and there are, almost, 101 to 105 death reports resulting from cancer (2). This disease will continue to be an important factor exacerbating the global disease burden in the future. It is expected the incidence rate of cancer experience considerable growth, from 10 million in 2000 to 15 million in 2020; about $60 \%$ of new cases are seen in less developed parts of the world (3). With 13\%

*Corresponding Author:

\section{Azin Chakeri}

MSc in Psychiatric Nursing, Islamic

Azad University, Tehran Medical Branch, Tehran, Iran and Faculty member of Islamic Azad University, Gramsar branch, Garmsar, Iran

Email: azinchakeri2000@yahoo.com incidence rate, lung cancer is the most common type of cancer; breast cancer is in the second place with 1.7 million and colon cancer occupies the third place with nearly 1.4 million (4). In general, lung cancer is the most fatal form of cancer throughout the world, so that $15 \%$ of people in United States of America who have developed lung survive a maximum of five years after being diagnosed by the doctor. Also, according to a report in 2008, lung cancer is the main death cause of 1.38 million people (5). Tumors' getting smaller over time and other medical indicators have come to be traditionally associated with treatment of cancer patients. Nowadays, in addition to these measures and indicators, other factors have been suggested, called as health-related quality of life, in assessing the process of advancement and treatment of cancer (6). Checking the quality of life as a key issue in the study of chronic diseases, especially cancer, has recently come to light. This disease affects the life quality of patients in all cases; similarly, suffering from cancer is one of the increasingly important issues in Iran and all over the world (7). Cancer patients experience both mental and physical problems, the main one of which is pain. Pain is a multidimensional phenomenon in cancer patients which affects all aspects of their life; it overshadows the quality of and, perhaps, quantity of life (8). Early 
detection of cancer would still be considered as fatal news for many patients and $3.1 \%$ of subjects experience anxiety and depression. It is equally stressful for the family of the patient and it will affect the family's economic situation and daily performance profoundly (8). Death anxiety is another common psychological side effect of cancer. With the progression of the disease and its associated symptoms, patients experience fear and pain, loneliness, suffering, punishment or loss of control, all of which are associated with death anxiety; this negative feeling can cause severe psychological disorders and affect the quality of life of these patients negatively. (9). Death anxiety makes the cancer patients come back to be hospitalized with the smallest symptom of complications, which, in turn, causes certain additional costs. Chemotherapy has come to be the most common treatment technique to destroy the cancer cells. Studies show treatment of cancer is associated with toxicity and side effects that reduce the patient's quality of life (10). Tele-nursing can be introduced as one of the ways enabling the nurses to promote acquire further training in nursing care and provide welfare for patients. Tele-nursing is a branch of remote medical care. Nurses can provide nursing care to the patients with help of communication and remote information technology through Tele-nursing. It,also, facilitates communication and exchange of knowledge and experience among nurses living in remote geographical areas. Tele-nursing reduces costs and improves the quality of nursing care (12). This method is an effective technique to improve public health and increase access to health care for the less provided individuals; it provides high flexibility in the innovation and creativity of nursing process and the expansion of professional nursing practices in various aspects such as training, research, management and delivery of clinical services (13). Given the increasing incidence of cancer and the significance impact of this disease on all dimensions of the quality of life of people and considering that harsh condition of cancer patients who are treated with chemotherapy, the present study was conducted to determine the impact of Tele-nursing method on enhancing the quality of life of cancer patients.

\section{Materials and Methods}

This research was a quasi-experimental study. The research areas included oncology departments of selected hospitals of Tehran University of Medical Sciences (Shariati and Khomeini). Samples included 60 men and women hospitalized on the mentioned wards when they were initially diagnosed with cancer (colon or lung, which was confirmed by pathology) and received treatment for the first time; sampling was conducted through continuous method. The questionnaire used to collect data in this study consists of two parts. The first part included demographic data (age, education, marital status and occupation) and the second part was a specific standard questionnaire to assess quality of life in patients with cancer (QLQ - C30), which was completed by the subjects. In this study, all subjects received training program through lecture, along with training manual in two two-hour sessions on two consecutive days, during hospitalization. Then, specific standardized questionnaires were completed by all subjects to assess the quality of life in patients with cancer (QLQ - C30). Then, the samples were randomly divided into two groups of intervention and control. Control group received no intervention except for the training program and manual; then, questionnaires of life quality were completed by this group 14 days after completing the first questionnaire; in regard with the intervention group, the subjects received counseling and Telenursing for 8 weeks and 2 calls a week. Finally, the specific standardized questionnaire was completed to assess the quality of life of cancer patients of the intervention group after 8 weeks of consultation. SPSS 17 and chi-square, Fisher, paired t-test and independent t-test statistical tests were used to analyze the collected data.

\section{Results}

The mean age of patients in the control and intervention groups turned out to be $43.44 \pm 9.07$ and $43.66 \pm 8.32$ years. Independent t-test results showed that the two study groups had no significant differences in mean age $(p$-value $=0.924)$. The patients in both groups were studied for some demographic data, such as gender, marital status, education level and occupation and the results of the Chi-square and exact Fisher tests showed the two groups were homogeneous in terms of gender, marital status, educational level and occupational groups (Table 1). The quality of life, and its related aspects, of both groups were analyzed at baseline and before training and after training using paired t-test; the results of this analysis showed that there was a statistically significant difference in both groups before and after training and the score of quality of life and both its aspects experienced considerable increase, indicating improvement after training (Table 2 ). Both groups, one of which just received training with the manuals and the other received distance learning in addition to training manuals, were compared together in regard with efficiency and productivity. Independent t-test results showed that the score of life quality and its aspects were similar in two groups before training and there was no statistically significant difference. But, quality of life and performance aspects and symptoms in both groups turned out to be statistically significant after training. However, the quality of life improved in both groups and this increase was higher in the intervention group who received distance learning, in addition to training manuals (Table 2). The score of the sizes of the performance aspect of the study was also examined and it was observed that the mean scores increased in both groups and independent t-test results showed that the two study groups were significantly different in size of the performance aspect and the scores of aspects of quality of life were higher in the intervention group (Table 3). 
Table 1: Frequency distribution of demographic

Percentage of patients under study in two groups of intervention and control - 2015

\begin{tabular}{|c|c|c|c|c|c|c|}
\hline \multicolumn{2}{|c|}{ Demographic characteristics } & \multicolumn{2}{|c|}{ Control group } & \multicolumn{2}{|c|}{ Intervention group } & \multirow[t]{2}{*}{ Test results } \\
\hline & & Frequency & Percent & Frequency & Percent & \\
\hline \multirow[t]{2}{*}{ Gender } & Female & 14 & 46.7 & 12 & 40 & \multirow{2}{*}{$\begin{array}{c}\chi^{2}=2.71 \\
d f=1, p- \\
\text { value }=0.602\end{array}$} \\
\hline & Male & 16 & 53.3 & 18 & 60 & \\
\hline \multirow{2}{*}{ Marital status } & Single & 12 & 40 & 7 & 23.3 & \multirow{2}{*}{$\begin{array}{c}\chi^{2}=1.93 \\
d f=1, p- \\
\text { value }=0.165\end{array}$} \\
\hline & Married & 18 & 60 & 23 & 76.7 & \\
\hline \multirow{4}{*}{$\begin{array}{c}\text { Educational } \\
\text { level }\end{array}$} & $\begin{array}{l}\text { Diploma and } \\
\text { Without }\end{array}$ & 13 & 43.3 & 13 & 43.3 & \multirow[t]{3}{*}{$\mathrm{p}$-value $=1 *$} \\
\hline & E.H.D & 3 & 10 & 13 & 43.3 & \\
\hline & B.A & 3 & 10 & 2 & 6.7 & \\
\hline & M.A or higher & 12 & 40 & 12 & 40 & \\
\hline \multirow[t]{4}{*}{ Occupation } & $\begin{array}{l}\text { Housekeeper } \\
\text { clerk }\end{array}$ & 7 & 25.9 & 7 & 24.1 & \multirow[t]{4}{*}{$\begin{array}{c}\mathrm{p}- \\
\text { value }=0.326^{*}\end{array}$} \\
\hline & Clerk & 8 & 29.6 & 15 & 51.7 & \\
\hline & Self-employed & 9 & 33.3 & 6 & 20.7 & \\
\hline & $\begin{array}{l}\text { College } \\
\text { student }\end{array}$ & 3 & 11.1 & 1 & 3.4 & \\
\hline
\end{tabular}

Table 2: comparison of quality of life and its aspects in two groups of intervention and control before and after intervention - 2015

\begin{tabular}{|c|c|c|c|c|c|}
\hline & Control & Intervention & \multicolumn{3}{|c|}{ Independent t-test } \\
\hline & S.D \pm mean & S.D \pm mean & $\mathbf{T}$ & df & p-value \\
\hline $\begin{array}{l}\text { Performance } \\
\text { aspect-before }\end{array}$ & $48.1418 .61 \pm$ & $43.5220 .71 \pm$ & 0.910 & 58 & 0.367 \\
\hline $\begin{array}{l}\text { Performance } \\
\text { aspect-after }\end{array}$ & $65.2314 .95 \pm$ & $82.078 .23 \pm$ & 5.401 & 58 & $<0.001$ \\
\hline $\begin{array}{c}\text { Results of } \\
\text { paired t-test }\end{array}$ & p-value $<0.001$ & p-value $<0.001$ & & & \\
\hline $\begin{array}{l}\text { Domain of } \\
\text { symptom- } \\
\text { before }\end{array}$ & $38.1115 .43 \pm$ & $35.0415 .82 \pm$ & 0.762 & 58 & 0.449 \\
\hline $\begin{array}{c}\text { Domain of } \\
\text { symptom- after }\end{array}$ & $69.1313 .24 \pm$ & $82.936 .72 \pm$ & 5.506 & 58 & $<0.001$ \\
\hline $\begin{array}{c}\text { Results of } \\
\text { paired t-test }\end{array}$ & p-value $<0.001$ & p-value $<0.001$ & & & \\
\hline $\begin{array}{c}\text { Total quality of } \\
\text { life-before }\end{array}$ & $43.4916 .66 \pm$ & $39.5717 .71 \pm$ & 0.881 & 58 & 0.382 \\
\hline $\begin{array}{c}\text { Total quality of } \\
\text { life-after }\end{array}$ & $67.0613 .38 \pm$ & $82.936 .72 \pm$ & 5.802 & 58 & $<0.001$ \\
\hline $\begin{array}{c}\text { Results of } \\
\text { paired t-test }\end{array}$ & p-value $<0.001$ & p-value $<0.001$ & & & \\
\hline
\end{tabular}


Table 3: Comparison of average size of the

Functional aspects of intervention and control groups after the intervention - 2015

\begin{tabular}{|c|c|c|c|c|c|}
\hline $\begin{array}{c}\text { Performance } \\
\text { aspects }\end{array}$ & Control & Intervention & \multicolumn{3}{|c|}{ Independent t-test } \\
\cline { 2 - 6 } & S.D \pm mean & S.D \pm mean & T & df & 58 \\
\hline $\begin{array}{c}\text { Physical } \\
\text { dimension }\end{array}$ & $67.7717 .77 \pm$ & $809.42 \pm$ & 3.32 & 58 & $<0.001$ \\
\hline Action dimension & $74.4422 .63 \pm$ & $89.4414 .17 \pm$ & 3.07 & 58 & $<0.001$ \\
\hline $\begin{array}{c}\text { Emotional } \\
\text { dimension }\end{array}$ & $44.1621 .45 \pm$ & $72.7713 .65 \pm$ & 6.16 & & 58 \\
\hline $\begin{array}{c}\text { Cognition } \\
\text { dimension }\end{array}$ & $89.4417 .22 \pm$ & $99.443 .04 \pm$ & 2.13 & & 50.001 \\
\hline Social dimension & $68.8819 .44 \pm$ & $81.1118 .94 \pm$ & 2.46 & & 0.022 \\
\hline
\end{tabular}

\section{Discussion}

The results of this study showed that the mean score of the quality of life of patients under study were 43.49 and 39.57 in two groups of intervention and control before training. It turned out that the patients' quality of life was lower than the average score demarcated by the research tools. However, after providing training manuals for the control group, their score of quality of life increased up to 67.06; in regard with the intervention group, the subjects of which recieved training manuals and Tele-nursing, the quality of life enhanced up to 82.93; these rates were higher than the average score determined by the tool. The independent t-test results of this study showed statistically significant differences between the two groups after the intervention. Petiteh et al. research, conducted to investigate the effect of Tele-nursing on the lives of people with lung cancer in Virginia in 2014, stated that Tele-nursing technology could be quite useful in reducing the symptoms of the disease, improving emotional-mental status as well as teaching self-care behaviors and ultimately increasing in the quality of life (14). According to the results of Van den et al., entitled "Evaluation of a telemedicine support system on the quality of life in patients with head and neck cancer after surgery and discharge from the hospital", there was significant difference in measuring the quality of life in both intervention and control groups; they believed that Telephone follow-up care was effective on the quality of life of cancer patients (15), a finding which is quite consistent with the results of the present study. Two aspects of performances and symptoms were less than 50 in both groups before the training; however, these two elements increased after training in both groups, getting up to a little higher than the median, indicating the enhancement of the symptoms and performance. Independent t-test showed statistically significant difference in both aspects between the two groups after the intervention. The results in the line with examining size of performance aspects of quality of life showed that emotional dimension, with an average of 44.16, turned out to be the lowest among other dimensions in the control group and other dimensions received a score above mean of 50. All aspects of the intervention group subjects acquired a score over 70; also, independent t-test showed that both groups were significantly different after the intervention. Finally, it is noteworthy that comparison between the scores of life quality in both groups was not statistically significant before the intervention, showing that both study groups were homogeneous, while this difference was statistically significant after the intervention, and the group receiving Tele-nursing and training manuals showed a greater increase, implying the positive impact of Telenursing. According to the results of Galliano et al research in 2013, which was conducted in order to study the impact of the remote care system on improving the quality of life for the patients with breast cancer in Spain, the positive efficiency of a phone rehabilitation system as a useful technique during complementary therapies for patients with cancer was confirmed (16). Zakeri Moghaddam et al in 2008(17), Shojaee in 2011 (18), Imani et al in 2012(19), Fakhazadeh et al (20) in their in 2013 examined the possible impact of Telenursing; the results of their study indicated that training is quite useful, a fact which is consistent with the findings of the present study. Thus, Tele-nursing can be an effective way to improve the quality of life of patients with cancer and it can be used to improve the performance of patients and also the symptoms of the disease.

\section{Acknowledgments}

Hereby, the staff of the Oncology wards of Shariati Hospital and Imam Khomeini who helped us during the completion of the present research are wholeheartedly thanked and appreciated.

\section{Reference}

1. ImaniPour.M, (2009), "Cancer Nursing Fundamentals," Second Edition, Tehran: Publication of Toefeh with collaboration of Publication Bashar, page 3

2. Aghaei.O (2012), "A look at the secretive disease of the 21st century, the cancer," Tehran: Anna medicine Publication, page 36

3. Ramezani Daryasari.R, Donelou.M, Khoshideh .MM, (2008), Tehran, First Edition, published by the Ministry of Health, Page 7.

4. Ferlay.j, Hairim.Sh, Freddle.B, et al., (2010), estimates of worldwide burden of cancer in 2008, international journal of cancer, 127(12):2893917.

5. Lortet.J, Ahmedin.J, Freddie.B, et al .,(2015), Golobal cancer statistics 2012, A cancer journal for clinicians, vol:65, issue:2, pp:87-108. 
6. Montazery.A, (2007), "The quality of life of cancer patients," weekly of white, No. 89, February, page 3

7. Safaee.A, Moghimi Dehkourdi.B, Tabatabee.H et al., (2007), "Quality of life and its influencing factors on patients with breast cancer undergoing chemotherapy, Journal of Epidemiology, Vol. 3, No. 4, pp. 61-66

8. Akhondzadeh.K, (2011), "Pain in cancer with nursing approach," first edition, published by University of Medical Sciences, page 2

9. Ramezani Daryasari.R, Doneleo.M, Khoshydeh.MM, (2008), Tehran, First Edition, published by the Ministry of Health, Page 7

10. Bahrami.N, Mourady.M, Kalantary.Z et al., (2013), "Death anxiety and its relation to quality of life for women with cancer," Journal of Nursing of Iran, Volume 26, No. 82, July 2013, pp. 51-61

11. Zeyghamy.Sh, Houshmand.P, Koushyar.MM, et al., (2008), "Evaluating quality of life of cancer patients undergoing chemotherapy," Journal of Faculty of Nursing and Midwifery, Hamedan, Volume 16, No. 1 , pages 5-10

12. Masserrat.E, Samady.N, Mohammadi.R, et al., (2011), "Tele-nursing: the appropriate option for improvement in the process of training patient, health and care Journal, Vol. XIII, No. 3, pp. 47-52

13. Darvish.A, (2014), "Medical IT," First Edition," Tehran: Anna medicine Publication, page 57

14. petitte.TM, Narsavage.GL,Coole.ch ,et al ., (2014), Feasibility Study: "Home Telemonitoring for Patients With Lung Cancer in a Mountainous Rural Area", 41(2):153-161.
15. Vanden Brink.JL, Moorman.PW, Deboer.MF,et al., (2007), "Impact on Quality of Life of a Telemedicine System Supporting Head and Neck Cancer Patients", Journal of the American Medical Informatics Association, Mar-Apr 14(2);pp:198205.

16. NoeliaGaliano. $\mathrm{C}$, Angelica ariza .G, Irene Cantarero. V, et al., (2013), "Telehealth System (e cuidate) to Improve Quality of Life in Breast Cancer Survivors": rationale and Study Protocol for a Randomized Clinical Trial, http:// www.trialsjournal.com/content/14/1/187.

17. Fakharzadeh. L ,Shahbazian . H, Salehinia . H, et al.,(2013)," Effect of telenursing on glycosylated hemoglobin (HbAlc) and anthropometric indexes in type 2 diabetic patients", modern care journal, 10 (2): 101-107

18. Zakerimoghadam.M , Nesari.M, Rajab.A, et al., (2010)," Effect of telephone follow-up on adherence to a diabetes therapeutic regimen", Japan Journal of Nursing Science, Volume:7,issue:2,pp:121-128.

19. Imani.A, Dabirian .A, Safavibiat .Z, (2015),"Examining the empact of nurse notification by phone (telenursing) on anxiety level of hospitalized patients family in intensive care unit", Psychiatric and Mental Health Nursing,9(4);22-28.

20. Shojaee. A, Nehrir.B, Naderi.N, et al.,(2013), Assessment of the effect of patient's education and telephone follow up by nurse on readmissions of the patients with heart failure, Iran Journal Crit Care Nurs ,6(1):29-38. 